\title{
Unraveling the Molecular Details of the Complete Mechanism That Governs the Synthesis of Prostaglandin G2 Catalyzed by Cyclooxygenase-2
}

Anna Cebrián-Prats, ${ }^{\dagger}$ Àngels González-Lafont, ${ }^{\dagger, \ddagger \odot}$ and José M. Lluch ${ }^{*, \dagger}, \ddagger \odot$

${ }^{\dagger}$ Departament de Química and ${ }^{\ddagger}$ Institut de Biotecnologia i de Biomedicina (IBB), Universitat Autònoma de Barcelona, Bellaterra, 08193 Barcelona, Spain

Supporting Information

ABSTRACT: Cyclooxygenase-2 (COX-2) is the key enzyme involved in the synthesis pathway of prostaglandin G2 (PGG2) by transformation of arachidonic acid (AA). Although COX-2 is one of the principal pharmacological targets by the implication of PGG2 in several human diseases, the classical all-radical mechanism proposed for COX-2 catalysis has never been validated at the molecular level. Herein, molecular dynamics simulations and quantum mechanics/molecular mechanics $(\mathrm{QM} / \mathrm{MM})$ calculations were combined to analyze the six steps of the all-radical mechanism. The results show that $\mathrm{O}_{2}$ addition on $\mathrm{C}_{11}$ of $\mathrm{AA}$ can follow an antarafacial or suprafacial approach with respect to tyrosine 385 , but only the antarafacial addition leads to the product with the correct $11 \mathrm{R}$ stereochemistry as established in the mechanistic proposal. Moreover, only the reaction pathway coming from the antarafacial intermediate describes a viable 8,12-cyclization to form the prostaglandin-like bicyclo endoperoxide that finally leads, by kinetic control, to PGG2 with the $15 S$ stereochemistry found experimentally. The formation of the more stable trans ring isomer of natural PGG2 in an enzymatic environment is also explained. Our molecular analysis shows how COX-2 uses its relatively narrow channel in the active site to restrain certain conformational changes of AA and of the reaction intermediates, so that the PGG2 enzymatic synthesis turns out to be highly regiospecific and stereospecific. A more recent 10-step carbocation-based mechanistic proposal has been discarded.

\section{INTRODUCTION}

Cyclooxygenase-2 (COX-2) is a membrane-associated homodimeric bifunctional hemoprotein that catalyzes the oxygenation of several polyunsaturated fatty acids. ${ }^{1}$ Arachidonic acid (AA, 20:4 n-6), released from phospholipid membranes, is its main substrate leading to the generation of prostaglandins, whose production is associated to many human pathologies, including inflammation, cardiovascular diseases, and cancer. ${ }^{2}$ COX-2 has a crucial relevance in pharmacology because it is a target of the nonsteroidal anti-inflammatory drugs such as, for instance, aspirin, ibuprofen, and diclofenac, thus producing the well-known analgesic, antipyretic, and anti-inflammatory effects. $^{3-8}$

Each monomer has two mechanistically coupled, spatially distinct active sites. ${ }^{1}$ AA binds within the cyclooxygenase active site at the end of a hydrophobic channel that extends up to the membrane-binding region. After $\mathrm{C}_{13}$ hydrogen abstraction from $\mathrm{AA}$, the addition of two $\mathrm{O}_{2}$ molecules converts $\mathrm{AA}$ to prostaglandin G2 (PGG2; see Scheme 1). PGG2 is then released to the heme-containing peroxidase active site located near the protein surface, where its 15 -hydroperoxide group is reduced to give prostaglandin $\mathrm{H} 2$ ( $\mathrm{PGH} 2)$. The peroxidase activity can work independently of the cyclooxygenase one. ${ }^{2}$ Conversely, cyclooxygenase activity is peroxide-dependent. In the resting state of COX-2, the peroxidase active site contains a
Scheme 1. Prostaglandin G2 (PGG2)

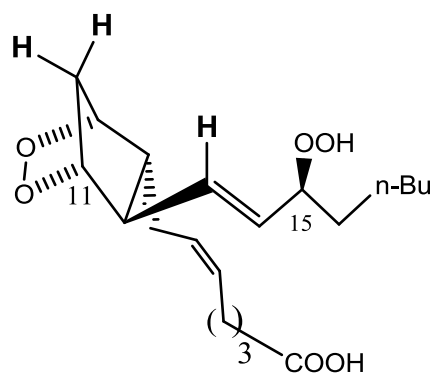

$\mathrm{Fe}^{3+}$-protoporphyrin IX group. ${ }^{9}$ An alkyl hydroperoxide activates the heme group by means of a two-electron oxidation, yielding the corresponding alcohol and an oxy-ferryl protoporphyrin IX radical cation, which, in turn, is reduced by an intramolecular electron transfer from the Tyr385 placed in the cyclooxygenase active site. The so-formed tyrosyl radical initiates the catalytic cycle in the cyclooxygenase active site when the substrate AA occupies this site. Electron para-

Received: December 20, 2018

Accepted: December 31, 2018

Published: January 25, 2019 


\section{Scheme 2. All-Radical Mechanism}
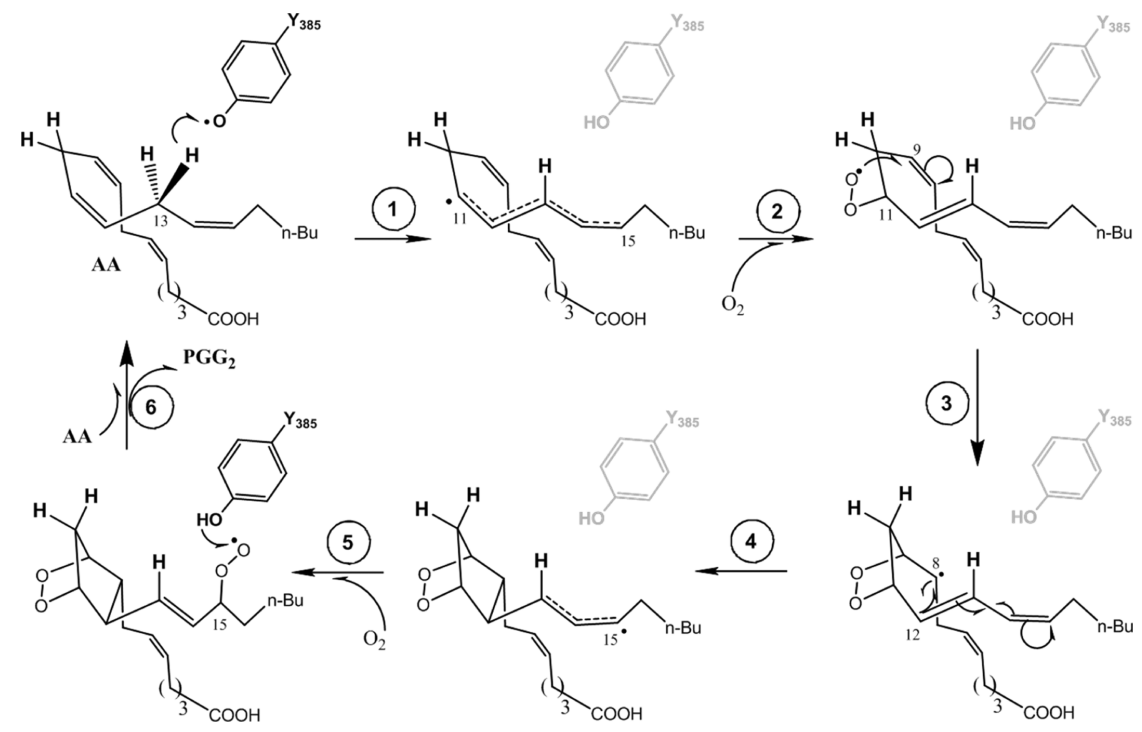

magnetic resonance spectroscopy shows the formation of Tyr385 radical after the addition of an alkyl hydroperoxide ${ }^{9,10}$ and the appearance of an arachidonate radical following the addition of $\mathrm{AA}$. $^{10}$

So far, the only existing unambiguous crystal structure of AA bound in the cyclooxygenase active site of COX-2 in a productive conformation ${ }^{1,11}$ corresponds to its complex with the $\mathrm{Co}^{3+}$-protoporphyrin IX-reconstituted murine COX-2 (muCOX-2-AA complex; PDB code 3HS5) determined to $2.1 \AA$ that lacks both peroxidase and cyclooxygenase activities. There are no significant structural differences between both enzyme monomers $\mathrm{A}$ and $\mathrm{B}$, although $\mathrm{AA}$ adopts very different conformations within the cyclooxygenase active sites of each monomer. Very interestingly, AA in monomer A exhibits a nonproductive binding mode (unable to react) with the AA carboxylate interacting with Tyr385 and Ser530 at the apex of the channel. Conversely, an "L-shaped" productive binding configuration of AA is observed in monomer B such that the AA carboxylate lies near the side chains of Arg120 and Tyr355 at the opening of the channel, whereas the AA $\omega$-end is encased by residues Phe205, Phe209, Val228, Val344, Phe381, and Leu534 that form a hydrophobic groove above Ser530. The $\mathrm{C}_{13}$ carbon atom of $\mathrm{AA}$ is positioned $2.95 \AA$ below the phenolic oxygen of Tyr385, ready to start the cyclooxygenase reaction by abstraction of a $\mathrm{C}_{13}$ hydrogen. This way, only one monomer (the catalytic one) of the COX-2 homodimer is active at a given time. ${ }^{12}$

There is a general agreement ${ }^{13-15}$ about the mechanism that rules such an important enzyme reaction in the cyclooxygenase active site. The classical six-step all-radical mechanism (see Scheme 2) derives from proposals by Hamberg and Samuelsson more than 50 years ago. ${ }^{16-19}$ After a $\mathrm{C}_{13}$ hydrogen abstraction from AA by a tyrosyl radical, a delocalized $C_{11}-C_{15}$ pentadienyl radical is generated (step 1). An antarafacial $\mathrm{O}_{2}$ addition at $\mathrm{C}_{11}$ yields a $11 \mathrm{R}$ peroxyl radical (step 2), which yields a $\mathrm{C}_{8}$-radical cyclic endoperoxide by means of a 9,11cyclization (step 3). Step 4 consists of an 8,12-cyclization leading to a bicyclo endoperoxide and a $\mathrm{C}_{13}-\mathrm{C}_{15}$ allyl radical. A second $\mathrm{O}_{2}$ addition at the $15 \mathrm{~S}$ position (step 5) and a back hydrogen transfer from Tyr385 to the peroxyl radical at $\mathrm{C}_{15}$ (step 6) finally give PGG2.
However, Dean and Dean ${ }^{10}$ proposed later an alternative 10step carbocation-based mechanism. After $\mathrm{C}_{13}$ hydrogen abstraction from AA, a sigmatropic hydrogen transfer from $\mathrm{C}_{10}$ to $\mathrm{C}_{13}$ takes place, forming a delocalized $\mathrm{C}_{8}-\mathrm{C}_{12}$ pentadienyl radical, followed by an electron transfer from $\mathrm{C}_{10}$ to the heme group, thus producing a carbocation at $\mathrm{C}_{10}$ (see Scheme 3). Then, an 8,12-cyclization, a back electron transfer

Scheme 3. Formation of the Carbocation in $\mathrm{C}_{10}$ according to the Carbocation-Based Mechanism
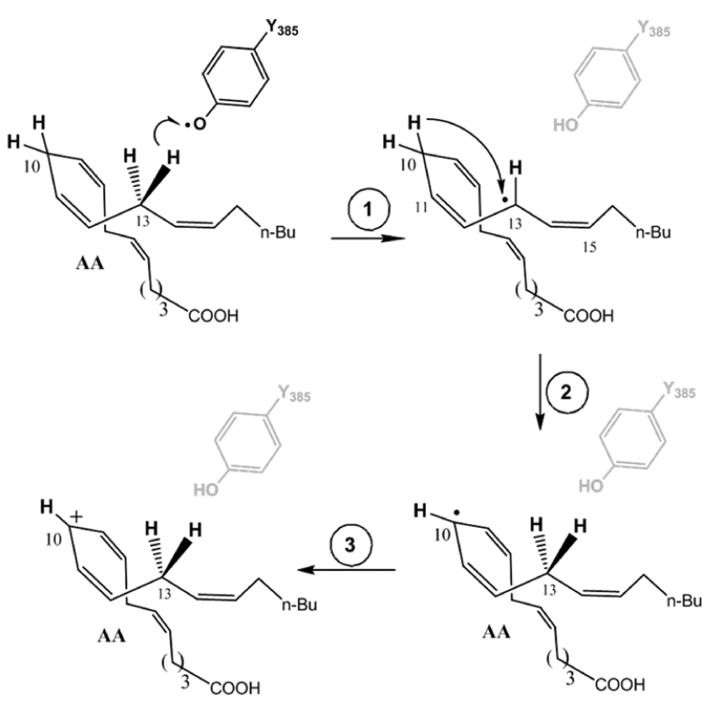

from the heme group to $\mathrm{C}_{11}$, an $\mathrm{O}_{2}$ addition at $\mathrm{C}_{11}$, a 9,11cyclization, a hydrogen transfer from $\mathrm{C}_{13}$ to $\mathrm{C}_{10}$, a second $\mathrm{O}_{2}$ addition at $\mathrm{C}_{15}$, and finally a back hydrogen transfer from Tyr385 to the peroxyl radical at $C_{15}$ lead to PGG2. Several important points that Dean and Dean argued in favor of their carbocation-based mechanism were:

a Autoxidative cyclization of polyunsaturated fatty acid hydroperoxides in solution to form prostaglandin-like bicyclo endoperoxides through an all-radical mechanism highly favors cis-disubstituted cyclopentane isomers, ${ }^{20}$ in clear opposition to the trans isomers corresponding to the natural prostaglandins generated by COX-2. 
b If 10,10-difluoroarachidonic acid is the substrate, COX enzymes do not generate any cyclic prostaglandin-like products, but acyclic alcohols such as 10,10-difluoro$11 S$-hydroxyeicosatetraenoic acid. ${ }^{21}$ Thus, it seems that the existence of hydrogen atoms at $\mathrm{C}_{10}$ would be required for the formation of prostaglandins.

c Chirality at $\mathrm{C}_{15}$ is supposed to be better explained when the $\mathrm{C}_{10}-\mathrm{C}_{13}$ hydrogen shift occurs.

Very recently, Navratil et al. ${ }^{22}$ have studied the ex vivo deuterium isotope effect for the enzymatic oxidation (by COXs and lipoxygenases) of AA by macrophages. They have found that deuteration of $C_{10}$ promotes the formation of Lipoxin B4, likely by interfering with AA cyclization and shunting AA to the lipoxygenase pathway under physiological conditions.

To compare at a detailed molecular level the two different mechanisms explained above, in this work we present the first theoretical study of the complete mechanism of reaction corresponding to the conversion of AA to PGG2 catalyzed by the enzyme COX-2. To this aim, we have combined molecular dynamics simulations with quantum mechanics/molecular mechanics (QM/MM) calculations. We have devoted special attention to the analysis of the rearrangements of the AA inside the active site of COX-2 along the different steps of the mechanism and to the understanding of how COX-2 manages to get the catalytic control of the stereoselectivity and the regioselectivity of the reaction.

\section{COMPUTATIONAL METHODS}

2.1. System Setup. The first step of this study consists in the setup of the heme-containing homodimer enzyme COX-2 interacting with AA. To begin with, we built the enzyme based on the murine COX-2-AA complex (PDB code $3 \mathrm{HS} 5),{ }^{1}$ in which the protoporphyrin IX group is complexed to a $\mathrm{Co}^{3+}$ and the homodimer presents AA interacting in different conformations in each monomer. $\mathrm{Co}^{3+}$ was replaced by $\mathrm{Fe}^{3+}$, and the heme prosthetic group was tethered to the axial histidine ligand (His388) in order to prevent the dissociation from the complex during the simulation.

Concerning the AA structure, only the monomer B exhibits the productive binding configuration, whereas the inverted orientation of the substrate is observed in monomer A in the cyclooxygenase channel. It is important to note that the productive orientation places the $\mathrm{C}_{13}$ of $\mathrm{AA}$ near the Tyr385 allowing the abstraction of a $\mathrm{C}_{13}$ hydrogen. We therefore decide to model only monomer $\mathrm{B}$ in order to study in detail each step of the catalytic mechanism. The AMBER ffl4SB force field ${ }^{23}$ was employed to define the protein residues, and the missing hydrogen atoms were added using the leap module of AMBER $14^{24}$ assuming a standard $\mathrm{pH}=7$ for the titrable residues. Five $\mathrm{Na}^{+}$ions were added into the protein surface to neutralize the total charge of the system. The total system was solvated in a cubic box of TIP3P water molecules ${ }^{25}$ of dimensions 91.1 $\AA \times 101.2 \AA \times 87.7 \AA$. The size of the cubic box was created considering a minimum cutoff of $15 \AA$ between the atoms of the enzyme and the edge of the periodic box, removing all the water molecules closer than $2.2 \AA$ to any atom of the protein or the substrate. The resulting system contains about 80600 atoms.

2.2. Parameterization. The partial atomic charges of the ferric penta-coordinate high spin group $\left(\mathrm{Fe}^{3+}\right)$ were obtained from the restrained electrostatic potential (RESP) ${ }^{26}$ method at the HF/6-31G $(d, p)$ level of theory. Then, the heme parameters were taken from a recent study ${ }^{27}$ and the axial histidine parameters were described by the general AMBER force field $(\mathrm{GAFF})^{28}$ using the residuegen and parmchk module of AMBER14. ${ }^{24}$ Concerning the AA, the parameters of its delocalized $\mathrm{C}_{11}-\mathrm{C}_{15}$ pentadienyl radical and its delocalized $\mathrm{C}_{13}-\mathrm{C}_{15}$ allyl radical were taken from a recent study. ${ }^{4}$

To parameterize the 10,10-difluoroarachidonic acid radical delocalized over the $C_{11}-C_{15}$ pentadienyl system, we calculated the partial atomic charges using the RESP method at the HF/6-31G(d,p) level of theory. Then, the parameters were obtained using the antechamber and parmchk module of AMBER14, combining them with some analogous parameters corresponding to the AA radical delocalized over the $C_{11}-C_{15}$ pentadienyl system.

Finally, the parameterization of the tyrosyl radical was performed starting with the optimization of the residue using the B3LYP functional ${ }^{29,30}$ and the 6-31G $(d, p)^{31,32}$ basis set for all atoms and then calculating the partial atomic charges by using the RESP method at the B3LYP/6-31G $(\mathrm{d}, \mathrm{p})$ level of theory with Gaussian09. ${ }^{33}$ The energy term corresponding to a stretching of a bond or a bending of an angle in the AMBER force field consist of a harmonic function that depends on a force constant. Then, the force constants associated to each bond or angle of the tyrosyl radical have been fitted to reproduce the $\mathrm{B} 3 \mathrm{LYP} / 6-31 \mathrm{G}(\mathrm{d}, \mathrm{p})$ potential energy profiles generated for the corresponding stretching or bending. In this case, the dihedral parameters have not been calculated, because they do not present any differences with respect to the tyrosine. The van der Waals parameters were taken from the GAFF force field of AMBER14, considering the oxygen radical as an ether or ester oxygen.

2.3. Molecular Dynamics Simulations. After proper setup and parameterization, the resulting systems with AA within the cyclooxygenase active site, including Tyr385 or the radical Tyr385 of monomer B of COX-2, were minimized following three MM minimization steps using the steepest descent and conjugate gradient methods. In the first step, we have applied harmonic restraints on the enzyme, heme prosthetic group, and the substrate, keeping the solvation waters free. In the second step, only the substrate and the heme prosthetic group have been restrained. The final minimization protocol was carried out applying restrains only on the protein side chains, the remaining system being free.

Then, two MD simulations have been performed under periodic boundary conditions, the first one including Tyr385 and the second one with the radical Tyr385. In both cases, the Michaelis complex was gradually heated from 0 to $300 \mathrm{~K}$ under the NVT ensemble (using Langevin dynamics), ${ }^{34}$ along $200 \mathrm{ps}$ with a weak restrain of $5 \mathrm{kcal} \mathrm{mol}^{-1} \AA^{-2}$ over the heme prosthetic group and the substrate. Starting from the last configuration of the NVT ensemble, a simulation of the system under the NPT ensemble was performed to control its density. Thus, we have carried out four steps of 10 ps at $300 \mathrm{~K}$ and 1 atm of pressure (using a isotropic weak-coupling algorithm and the Berendsen barostat) ${ }^{35}$ with a weak restrain on the residues side chains and then one last longer step of 160 ps to reach a density of the system around $1 \mathrm{~g} \mathrm{~cm}^{-3}$ (see Figure 1).

From the last configuration of the NPT ensemble (and, therefore, taking the final volume corresponding to $1 \mathrm{~atm}$ of pressure), an equilibration of $10 \mathrm{~ns}$ and the production simulation of $100 \mathrm{~ns}$ have been performed at $300 \mathrm{~K}$ using the NVT ensemble without any restraints. Along the $\mathrm{MD}$, the covalent bonds containing hydrogen were constrained using 


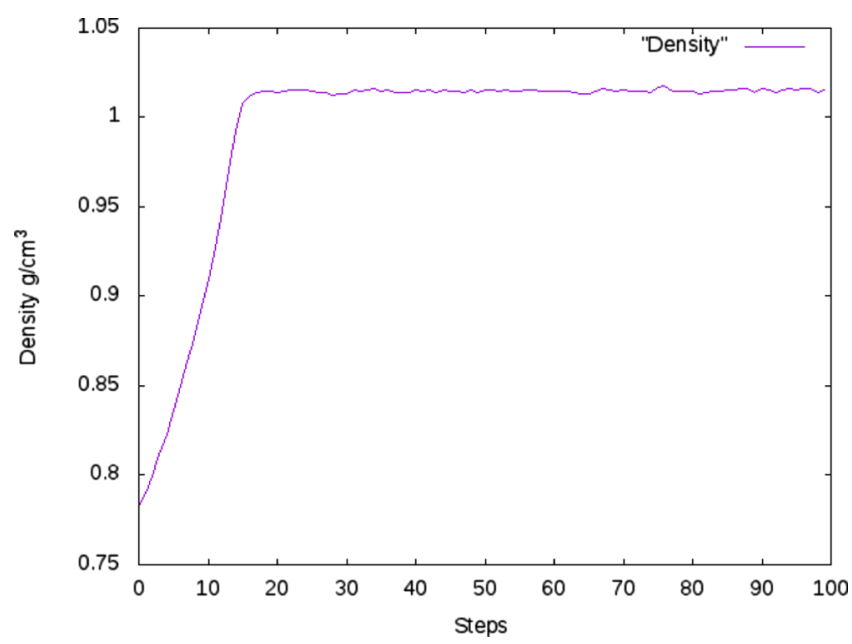

Figure 1. Evolution of the density along the NPT MD simulation of the COX-2-AA Michaelis complex including Tyr385. Each step stands for 2 ps.

the SHAKE algorithm, ${ }^{36}$ and the particle-mesh Ewald method $^{37}$ was used to treat long-range electrostatic interactions. The simulation was performed using the AMBER 14 GPU (CUDA) version of the PMEMD package. ${ }^{38,39}$ A time step of 2 fs has been used in all cases.

2.4. Quantum Mechanics/Molecular Mechanics Calculations. Representative snapshots of the MD simulation were used to perform the QM/MM calculations of each step of the catalytic mechanism. The $\mathrm{QM} / \mathrm{MM}$ calculations were performed using the modular program package ChemShell, ${ }^{40,41}$ combining Gaussian09 for the QM part and the DL POLY module ${ }^{42}$ in ChemShell for the MM part.

The AMBER force field was employed for the MM region and the electrostatic embedding scheme ${ }^{43}$ was used in all calculations to consider the polarizing effect of the enzyme over the QM region. Moreover, hydrogen link atoms have been employed to treat the QM/MM boundary with the charge-shift model, ${ }^{44}$ and no cutoffs were introduced for the nonbonding $\mathrm{MM}$ and $\mathrm{QM} / \mathrm{MM}$ interactions.

$\mathrm{QM} / \mathrm{MM}$ optimizations were carried out employing the limited-memory Broyden-Fletcher-Goldfard-Shanno (LBFGS) algorithm ${ }^{45}$ for energy minimizations. To build the potential energy profiles, a series of optimizations have been carried out imposing harmonic restrictions on the reaction coordinate, which, in general, increases with a step size of 0.2 A. For the transition state search, a combination of the partitioned rational function optimizer ${ }^{42}$ and the L-BFGS was used. These algorithms are implemented in the HDLCopt (Hybrid Delocalized Internal Coordinate Scheme $)^{42}$ module of Chemshell.

For each snapshot taken from the MD simulation, the corresponding QM/MM system includes all residues of the monomer $\mathrm{B}$ of $\mathrm{COX}-2$, the complete $\mathrm{AA}$ and the 500 water molecules closer to $\mathrm{C}_{11}$ of AA (roughly 10400 atoms). All residues and water molecules within a $15 \AA$ radius sphere centered on $\mathrm{C}_{11}$, and including the complete $\mathrm{AA}$, define the active region (around 2000 atoms) in which all atoms move freely during the optimization processes, whereas the rest of the system has been kept frozen.

In all calculations, the $\mathrm{QM}$ region was treated using the B3LYP hybrid functional and the 6-31G $(\mathrm{d}, \mathrm{p})$ basis set for all atoms. This subsystem presents different sizes depending on the particular step studied (see Figure S1). Because the Fe atom is in the peroxidase active site, it has been included in the MM region. Then, a doublet multiplicity has been imposed for the calculations of all reaction steps. For the reaction steps corresponding to an $\mathrm{O}_{2}$ addition, we have checked (see Table S1) that the $\mathrm{O}_{2}$ molecule has been introduced having a triplet character. The VMD program ${ }^{46}$ has been used to generate the pictures of molecules.

\section{RESULTS AND DISCUSSION}

3.1. Molecular Dynamics Simulations. Some time ago, two previous ${ }^{47,48} 10 \mathrm{~ns} \mathrm{MD}$ simulations of the COX2-AA and COX2-AA $\mathrm{C}_{13}$ radical complexes by Furse et al. showed the importance of dynamics to describe the features of these systems. In the present work, as explained above, after equilibration a $100 \mathrm{~ns} \mathrm{MD}$ simulation of $\mathrm{AA}$ within the cyclooxygenase active site including Tyr385 of monomer B of COX-2 has been carried out. The root mean-square deviation (RMSD) of the protein $\alpha$-carbons with respect to the first structure (see Figure 2) clearly shows that the protein is equilibrated, especially if the $\mathrm{N}$-terminal region is not considered.

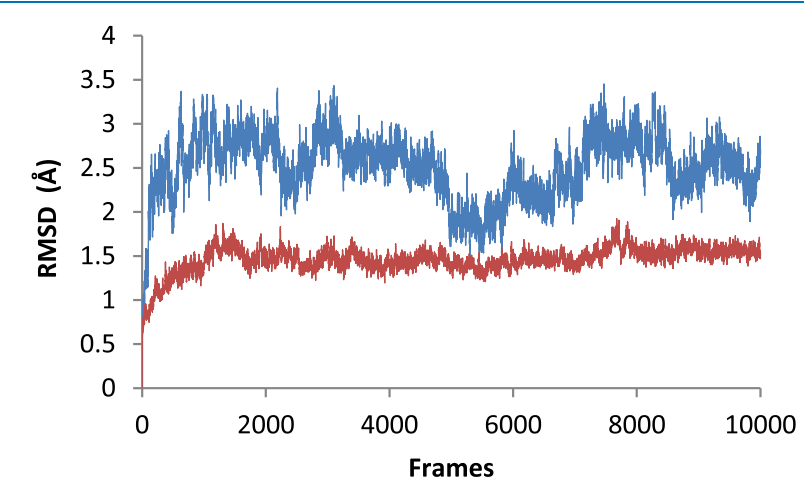

Figure 2. RMSD of the protein $\alpha$-carbons (blue line) and excluding the ones corresponding to the $\mathrm{N}$-terminal domain (red line) with respect to the first structure along the $100 \mathrm{~ns} \mathrm{MD}$ simulation of $\mathrm{AA}$ within the cyclooxygenase active site including Tyr385 of monomer B of COX-2. A frame has been taken each 10 ps.

From here on $\mathrm{H}_{13 \mathrm{~A}}$ will stand for the hydrogen of AA that will be abstracted. Then, we have followed (see Figure 3) the evolution of the distances $\mathrm{H}_{13 \mathrm{~A}}-\mathrm{OTyr} 385$ and $\mathrm{C}_{13}-\mathrm{OTyr} 385$ along the simulation. In practical, all the frames $d\left(\mathrm{H}_{13 \mathrm{~A}}-\right.$ OTyr385 $)>d\left(\mathrm{C}_{13}-\mathrm{OTyr} 385\right)$ along the first $90 \mathrm{~ns}$, although this relation is reversed in the last $10 \mathrm{~ns}$. In order to check how these distances change along longer $\mathrm{MD}$ simulations we have carried out an additional 50 ns simulation. As seen in Figure S2, no significant variation occurs within the time interval $100-150$ ns.

Taking one structure each $10 \mathrm{ps}$ along the first $100 \mathrm{~ns} \mathrm{MD}$ simulations and filtering them according to the conditions $d\left(\mathrm{H}_{13 \mathrm{~A}}-\mathrm{OTyr} 385\right) \leq 3 \AA$ and $d\left(\mathrm{H}_{13 \mathrm{~A}}-\mathrm{OTyr} 385\right)<d\left(\mathrm{C}_{13}-\right.$ OTyr385), we have selected those structures having characteristics adequate to initiate the reactive processes. The second condition ensures that the corresponding $\mathrm{C}_{13}-\mathrm{H}_{13 \mathrm{~A}}$ bond is properly oriented for the hydrogen abstraction. This way we have obtained 706 snapshots, which we call precatalytic structures, ready to react as soon as the tyrosyl radical is formed. To facilitate the analysis of the binding modes, these snapshots have been clustered using a RMSD of $1.3 \AA$ for the 


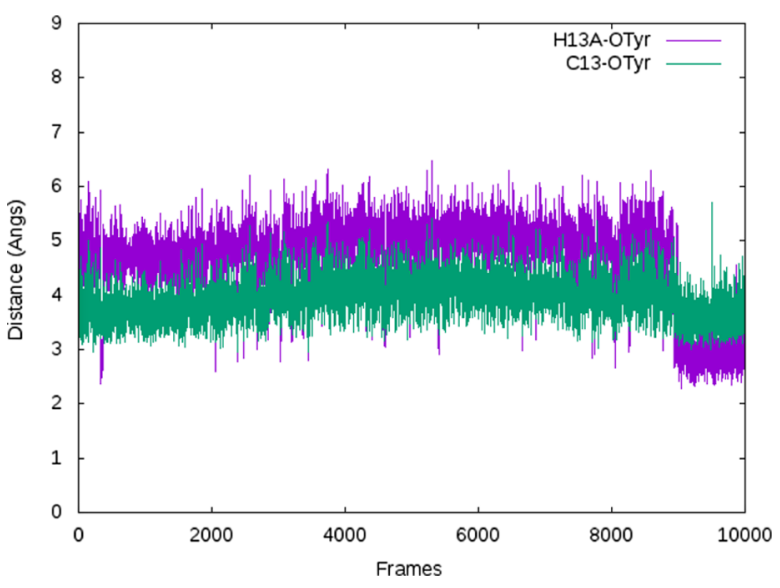

Figure 3. Evolution of the distances $\mathrm{H}_{13 \mathrm{~A}}-\mathrm{OTyr} 385$ (purple line) and $\mathrm{C}_{13}-\mathrm{OTyr} 385$ (green line) along the $100 \mathrm{~ns} \mathrm{MD}$ simulation of $\mathrm{AA}$ within the cyclooxygenase active site including Tyr385 of monomer B of COX-2. A frame has been taken each 10 ps.

heavy atoms of AA. The two more populated clusters have been represented in Figure 4. Our MD simulation reproduces

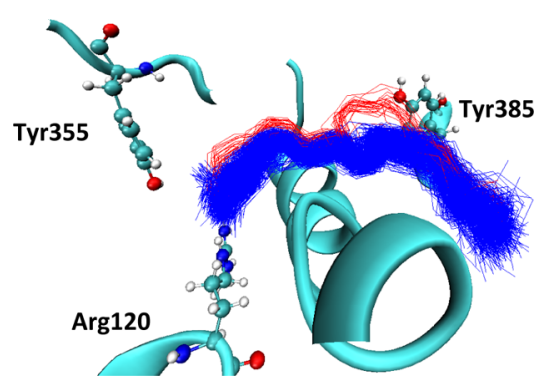

Figure 4. Two more populated clusters (the first one in blue, the second one in red) of the precatalytic structures using a RMSD of 1.3 $\AA$ for the heavy atoms of AA.

very well the "L-shaped" productive binding configuration of $\mathrm{AA}$ as observed in the above mentioned crystal structure by Vecchio et al. ${ }^{1}$ The AA carboxylate lies near the side chains of Arg120 and Tyr355 at the opening of the channel, whereas the AA $\omega$-end extends along the hydrophobic groove above Ser530, with the $C_{13}$ carbon atom of AA located below and near the phenolic oxygen of Tyr385.

On the other hand, given that the peroxidase cycle occurs independently of the cyclooxygenase activity, AA could occupy the cyclooxygenase site already containing a tyrosyl radical. Then, we have also run a $100 \mathrm{~ns}$ MD simulation of AA within the cyclooxygenase active site including the Tyr $385^{\circ}$ radical of monomer $\mathrm{B}$ of COX-2. The analysis of the evolution of the distances $\mathrm{H}_{13 \mathrm{~A}}-{ }^{\bullet} \mathrm{O}$ Tyr385 and $\mathrm{C}_{13}-{ }^{\bullet} \mathrm{O}$ Tyr385 along the simulation (see Figure S3) shows structures ready to react similar to the ones obtained with Tyr385.
3.2. Quantum Mechanics/Molecular Mechanics Calculations. 3.2.1. All-Radical Mechanism. To start QM/MM calculations for the all-radical mechanism (see Scheme 2), we have selected two of the precatalytic snapshots obtained above by filtering the structures shown in Figure 3. In particular, the distances $\mathrm{H}_{13 \mathrm{~A}}-\mathrm{OTyr} 385$ and $\mathrm{C}_{13}-\mathrm{OTyr} 385$ for snapshot I are 2.62 and $3.25 \AA$, respectively, and for snapshot II are 2.36 and $3.41 \AA$, also respectively. For each snapshot, we have first removed the phenolic hydrogen atom of Tyr385, and we have optimized the corresponding reactant structures. Because the first step of the all-radical mechanism is $\mathrm{H}_{13 \mathrm{~A}}$ abstraction from AA by the tyrosyl radical, then we have built the potential energy profile along the corresponding reaction coordinate, in this case defined as the difference between the distances corresponding to the breaking bond $\left(\mathrm{C}_{13}-\mathrm{H}_{13 \mathrm{~A}}\right)$ and the forming bond $\left(\mathrm{H}_{13 \mathrm{~A}}-\mathrm{OTyr} 385\right)$. The calculation of each profile has been repeated forward and backward until convergence to avoid hysteresis. The distances relatives to the three atoms that directly participate in the breaking/ forming bonds for the reactants, transition state structures, and products, along with the potential energy barriers are given in Table 1. As for these three atoms, once optimized, the reactants corresponding to the two snapshots exhibit some differences. This fact is normal when the substrate is as long and flexible as AA. In these cases, there exists a big dispersion $^{49-52}$ of the pre-catalytic structures due to the huge number of rearrangements that, for instance, AA can adopt within the configurational space. This geometry dispersion at the reactants does not usually produce significant changes in the reaction mechanism (the main goal of this paper), but in the potential energy barriers. In fact, the evolution along the reaction path of the reactants in snapshots I and II practically matches. $\mathrm{C}_{13}$ and $\mathrm{O}$ heavy atoms approach each other up to the transition state structure to facilitate the hydrogen transfer and then recover their original distance at the product. The geometries of both transition state structures around the transferring $\mathrm{H}_{13 \mathrm{~A}}$ are quite similar. In spite of that, the potential energy barriers differ by $4 \mathrm{kcal} / \mathrm{mol}$. As in previously studied enzyme reactions, ${ }^{49-51}$ the dispersion in energy barriers is not due to different transition state structures, but to the reactants' dispersion. Anyway, the values we have obtained are reasonable in comparison with recent measurements ${ }^{53}$ of the rate constants for oxidation of AA by COX-2 at $30{ }^{\circ} \mathrm{C} \quad\left(k_{\text {cat }}=16.7 \mathrm{~s}^{-1}\right.$, what, according to conventional transition state theory, corresponds to a phenomenological free energy barrier of $16 \mathrm{kcal} / \mathrm{mol}$ ).

The optimized products of the first step are AA radicals delocalized over the $C_{11}-C_{15}$ planar pentadienyl system. From here on we will describe the subsequent steps of the all-radical mechanism for the two parallel reaction paths derived from each snapshot, which have been studied in an identical manner. We will see that the main features of both reactions pathways are qualitatively identical, which reinforces the obtained

Table 1. Distances $(\AA ̊)$ Relatives to the Three Atoms That Directly Participate in the Breaking/Forming Bonds for the Reactants, Transition State Structures, and Products, along with the Potential Energy Barriers (kcal/mol) Corresponding to the $\mathrm{H}_{13 \mathrm{~A}}$ Abstraction from AA by the Tyrosyl Radical for the Snapshots I and $\mathrm{II}^{a}$

$\begin{array}{ccccccccccc}\text { structure } & d(\mathrm{C}-\mathrm{H})_{\mathrm{R}} & d(\mathrm{H}-\mathrm{O})_{\mathrm{R}} & d(\mathrm{C}-\mathrm{O})_{\mathrm{R}} & d(\mathrm{C}-\mathrm{H})_{\mathrm{TS}} & d(\mathrm{H}-\mathrm{O})_{\mathrm{TS}} & d(\mathrm{C}-\mathrm{O})_{\mathrm{TS}} & d(\mathrm{C}-\mathrm{H})_{\mathrm{P}} & d(\mathrm{H}-\mathrm{O})_{\mathrm{P}} & d(\mathrm{C}-\mathrm{O})_{\mathrm{P}} & \Delta E^{\ddagger} \\ \text { snapshot I } & 1.09 & 2.66 & 3.32 & 1.31 & 1.28 & 2.59 & 2.53 & 0.97 & 3.40 & 20.8 \\ \text { snapshot II } & 1.09 & 2.49 & 3.37 & 1.30 & 1.28 & 2.58 & 2.53 & 0.97 & 3.49 & 16.4\end{array}$

${ }^{a} \mathrm{C}, \mathrm{H}$, and $\mathrm{O}$ stand, respectively, for $\mathrm{C}_{13}, \mathrm{H}_{13 \mathrm{~A}}$, and $\mathrm{O}$ of Tyrosyl radical. 
conclusions. To study the second step, addition of an oxygen molecule to $C_{11}$, we have chosen different possible starting positions of the oxygen molecule. Taking $\mathrm{C}_{11}$ as the origin of coordinates, these molecules have been placed along the $x, y$, and $z$ Cartesian axes and along the bisector axes contained in the $x y, x z$, and $y z$ planes. ${ }^{54} 9,18$, and $26 \mathrm{O}_{2}$ molecules have been set to a distance of $2.5,3$, and $3.5 \AA$, respectively, from the closest oxygen atom to $C_{11}$. In all, 53 initial positions of the oxygen molecule for each snapshot. Figure 5 displays the arrangement of the oxygen molecules at a distance of $3.5 \AA$ from $\mathrm{C}_{11}$.

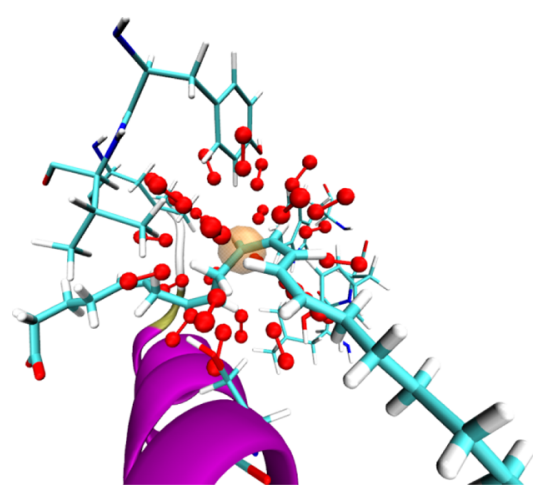

Figure 5. Arrangement of the oxygen molecules (in red) at a distance of $3.5 \AA$ from $\mathrm{C}_{11}$ (in orange).

QM/MM single point energy calculations have been carried out for the 53 positions and the higher energy structures have been discarded. The most stable structures have been optimized and taken as starting points to build the reaction path for the oxygen addition to $C_{11}$, with this distance chosen as the reaction coordinate. The potential energy barriers obtained for all the pathways that have been able to reach the products for both snapshots are given in Table 2 .

Note that the attack of the oxygen molecule to $C_{11}$ could be antarafacial (i.e., by the face of the $C_{11}-C_{15}$ pentadienyl system opposite to the tyrosyl radical), leading to an $11 \mathrm{R}$ stereochemistry, or suprafacial (by the same side where the tyrosyl radical is placed), giving an $11 \mathrm{~S}$ stereochemistry (see Figure S4 for a better view of the antarafacial/suprafacial concepts). The

Table 2. Potential Energy Barriers (kcal/mol)

Corresponding to the Oxygen Addition to $\mathrm{C}_{11}$ for all the Pathways That Have Been Able To Reach the Products for Snapshots I and II

\begin{tabular}{|c|c|c|c|}
\hline \multicolumn{2}{|c|}{ snapshot I } & \multicolumn{2}{|c|}{ snapshot II } \\
\hline$\Delta E^{\ddagger}$ & $\mathrm{O}_{2}$ attack & $\Delta E^{\ddagger}$ & $\mathrm{O}_{2}$ attack \\
\hline 49.5 & suprafacial & 49.3 & suprafacial \\
\hline 12.4 & non $^{a}$ supra/antara & 11.3 & non $^{a}$ supra/antara \\
\hline 9.3 & suprafacial & 8.7 & suprafacial \\
\hline 7.4 & suprafacial & 49.0 & suprafacial \\
\hline 7.5 & antarafacial & 5.8 & antarafacial \\
\hline 6.0 & suprafacial & 8.3 & suprafacial \\
\hline 7.5 & suprafacial & 9.7 & suprafacial \\
\hline 40.9 & antarafacial & & \\
\hline 35.8 & non $^{a}$ supra/antara & & \\
\hline 35.6 & non $^{a}$ supra/antara & & \\
\hline
\end{tabular}

${ }^{a}$ This oxygen attack can be classified neither as suprafacial nor as antarafacial. two possibilities can be visualized in Figure 6. Note the antarafacial approach (Figure 6a) is the only one that is

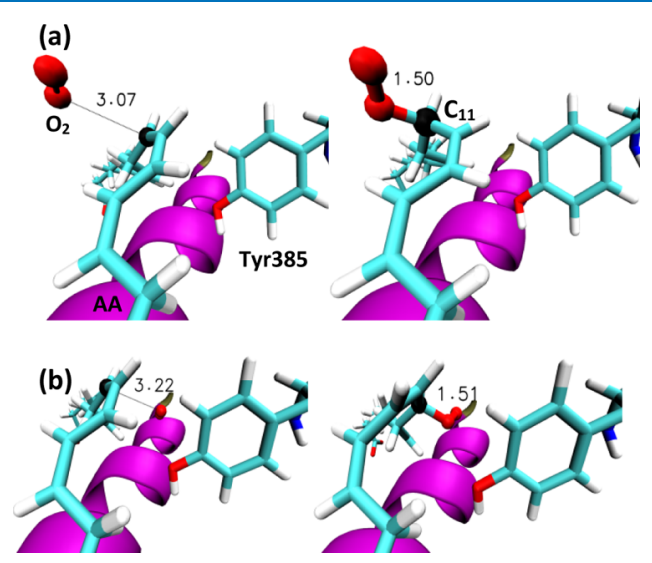

Figure 6. Optimized reactants (left) and products (right) corresponding to (a) antarafacial oxygen addition to $\mathrm{C}_{11}$ for snapshot I and (b) suprafacial oxygen addition for snapshot II. The distances are given in $\AA$. Carbon atom $\mathrm{C}_{11}$ is depicted in black and oxygen atoms in red.

obtained experimentally when PGG2 is the product. Our results show (the orientation of the $\mathrm{O}_{2}$ attack has been indicated for each reaction path in Table 2) that both the antarafacial and the suprafacial attacks appear to be possible, existing reaction paths that involve relatively small energy barriers in comparison with other steps of the global mechanism. The lowest potential energy barriers correspond to the suprafacial attack for snapshot I $(6.0 \mathrm{kcal} / \mathrm{mol})$ and to the antarafacial attack for the snapshot II $(5.8 \mathrm{kcal} / \mathrm{mol})$. The reactants and products (peroxyl radicals) corresponding to an antarafacial addition for snapshot I and a suprafacial addition for snapshot II are pictured in Figure 6. Then, it seems that is not necessarily the oxygen addition step, the one that imposes the antarafacial final configuration of PGG2 at $\mathrm{C}_{11}$.

We have started from the products generated with the lowest potential energy barriers corresponding to the antarafacial addition and the suprafacial addition for both snapshots to follow the formation of the $\mathrm{C}_{8}$-radical cyclic endoperoxides by means of a 9,11-cyclization. Prior to this third step, the just added oxygen molecule needs to rotate around the $\mathrm{C}_{11}-\mathrm{O}$ bond the unbonded oxygen in order to face $\mathrm{C}_{9}$. This rotation involves a small potential energy barrier of roughly $2 \mathrm{kcal} / \mathrm{mol}$. From these optimized rotated structures, the potential energy barriers for this first cyclization (the reaction coordinate is the $\mathrm{O}-\mathrm{C}_{9}$ distance) are given in Table 3. The reactants and products corresponding to the formation of the endoperoxide in an antarafacial case for the snapshot I and in a suprafacial case for snapshot II are pictured in Figure 7. It can be seen that the cyclizations coming from the suprafacial (11S) $\mathrm{O}_{2}$ additions are more favorable than the antarafacial

Table 3. Potential Energy Barriers ( $\mathrm{kcal} / \mathrm{mol}$ ) for the First Cyclization Corresponding to Snapshots I and II

\begin{tabular}{ccccc}
\multicolumn{2}{c}{ snapshot I } & & \multicolumn{2}{c}{ snapshot II } \\
\cline { 1 - 2 } \cline { 5 - 5 } \cline { 5 - 5 } & $\mathrm{O}_{2}$ attack & & $\Delta E^{\ddagger}$ & $\mathrm{O}_{2}$ attack \\
15.0 & suprafacial & & 10.0 & suprafacial \\
19.5 & antarafacial & & 20.0 & antarafacial
\end{tabular}



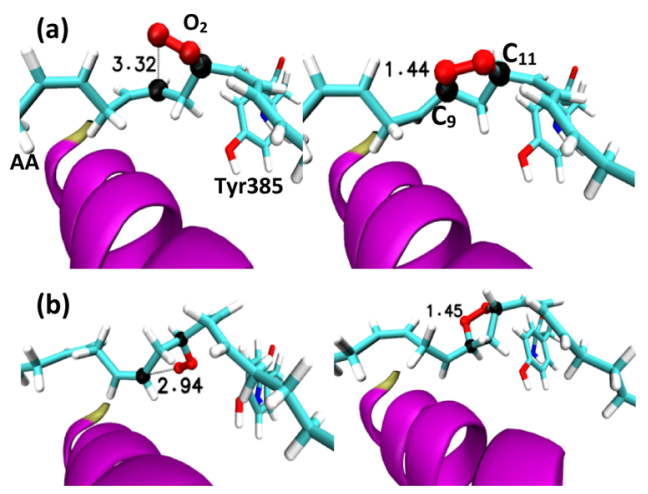

Figure 7. Optimized reactants (left) and products (right) for (a) antarafacial case (snapshot I) and (b) suprafacial case (snapshot II) for the first cyclization. The distances are given in $\AA$. Carbon atoms $\mathrm{C}_{9}$ and $\mathrm{C}_{11}$ are depicted in black and oxygen atoms in red.

(11R) ones. Then, this third step cannot explain the natural $11 \mathrm{R}$ configuration of PGG2 either.

Both snapshots behave in the same way for the 8,12cyclization, the fourth step, for which the $\mathrm{C}_{8}-\mathrm{C}_{12}$ distance was chosen to define the reaction coordinate. The antarafacial intermediates form the new $\mathrm{C}_{8}-\mathrm{C}_{12}$ bond, leading to a ring of 5 carbon atoms and a $\mathrm{C}_{13}-\mathrm{C}_{15}$ allyl radical, with potential energy barriers of 26.5 and $24.1 \mathrm{kcal} / \mathrm{mol}$ for snaphsots I and II, respectively. Conversely, the suprafacial intermediates are unable to produce this 8,12 -cyclization. When the formation of the $\mathrm{C}_{8}-\mathrm{C}_{12}$ bond is forced by means of shortening the distance between both carbon atoms, the strain imposed to the molecule provokes its rupture, in such a way that the $\mathrm{O}-\mathrm{O}$ and the $\mathrm{C}_{11}-\mathrm{C}_{12}$ bonds break, leading through a huge energy barrier (nearly $50 \mathrm{kcal} / \mathrm{mol}$ ) to a broken structure that has nothing to do with the one that has to be the product of this fourth step. At this point, it has to be emphasized that the substrate AA is a very long (20 carbon atoms) and flexible molecule (as a consequence of its multiple single bonds), but at the same time its structure is quite rigid as well, due to its four $\mathrm{C}=\mathrm{C}$ double bonds. This rigidity increases as $\mathrm{AA}$ is undergoing successive cyclizations. Therefore, a local chemical reaction at a given point of AA can require such conformational rearrangements, even in far regions of the substrate, that impose high energy barriers or even make the reaction impossible leading to the AA breakage. This is a very important factor that does not occur in enzymatic reactions involving small substrates, but that can be determinant when the substrate is as big as AA or other polyunsaturated fatty acids. In addition, we have to realize that the environment of residues that forms the enzyme active site restraints even more the conformational changes of AA and that this is the way how COX-2 manages to exert the catalytic control of the regioselectivity and stereoselectity of the reaction. Taking into account all that, we can identify the 8,12-cyclization as the responsible for the fact that only the antarafacial molecular oxygen attack, but not the suprafacial one, in the second step leads to the final PGG2, which, as a consequence, has an $11 \mathrm{R}$ configuration. This discriminating role of the 8,12-cyclization turns out to be likely the reason why Brash and cow. ${ }^{55}$ conclude that it is impossible to perturb the stereochemistry of $\mathrm{C}_{11}$ oxygenation in PGG2 by mutagenesis experiments.

At this point, a careful analysis of the stereochemistry of the cyclopentane ring that has been formed after the 8,12cyclization reveals that it presents a cis configuration (see
Figure 8a) for its side chains (the carboxylate end and the $\omega$ end). That is, the hydrogen atoms bonded to $C_{8}$ and $C_{12}$ (a)
(b)
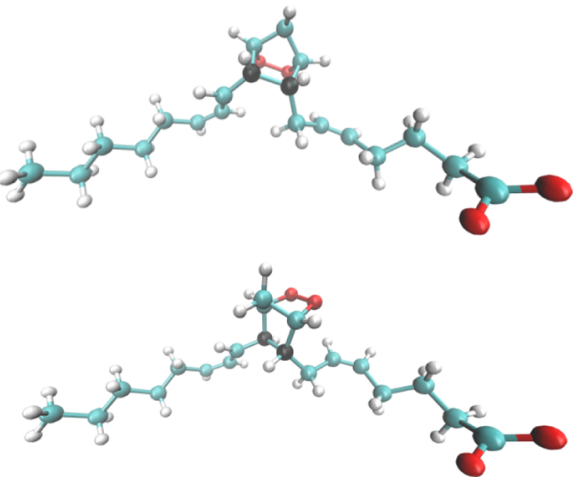

Figure 8. Prostaglandins containing (a) cis ring isomer or (b) trans ring isomer. Carbon atoms $\mathrm{C}_{8}$ and $\mathrm{C}_{12}$ are depicted in black and oxygen atoms in red.

appear on the same site of the cyclopentane. However, the natural prostaglandin produced by COX- 2 contains the trans ring isomer. Very interestingly, as mentioned in the Introduction, the autoxidative cyclizations of lipid hydroperoxides in solution to form prostaglandin-like bicyclo endoperoxides through an all-radical mechanism mostly produce cis ring isomers, the trans ring isomers being highly disfavored. $^{20}$ Then, COX-2 in some way manages to catalytically force the formation of the biologically active trans ring isomer. At the first thought, it could be supposed that the geometries of both ring isomers are quite different. However, an overlay between both (see Figure 8) clearly shows that the differences are very subtle and do not lie in the carboxylate end nor the $\omega$-end chains, but in the bicyclo endoperoxide, mainly in the position of the two oxygen atoms and carbon $\mathrm{C}_{10}$.

Let us re-examine the 8,12-cyclization from the antarafacial $\mathrm{C}_{8}$-radical cyclic endoperoxides. In Figure 9, we have shown the forward (red line) and backward (green line) potential energy profiles corresponding to the formation of the cis ring isomer of snapshot I. The red diamonds stand for the optimized stationary points of the cis reaction, which impose a potential energy barrier of $26.5 \mathrm{kcal} / \mathrm{mol}$, as mentioned above. The upper insets contain pictures of the reactant (left, pre cis) and product (right, cis). When the backward profile was repeated (blue line) with a shorter optimization step size $(0.1$ $\AA$ vs $0.2 \AA$ in the green line) it matches the previous cis one (green line) up to $3 \AA$ of the $\mathrm{C}_{8}-\mathrm{C}_{12}$ reaction coordinate, but between the values $3.2-3.5 \AA$ there appears an abrupt decrease of the energy barrier (roughly $10 \mathrm{kcal} / \mathrm{mol}$ ) that accompanies a deformation of the bicyclo endoperoxide going from a pre cis structure to a pre trans one. Starting from the new structure of the reactant (pre trans), a forward energy profile (purple line) leads to the natural trans ring isomer. The purple diamonds stand for the optimized stationary points of the trans reaction, which now impose a potential energy barrier of $23.4 \mathrm{kcal} / \mathrm{mol}$. The lower insets contain pictures of the reactant (left, pre trans) and product (right, trans). Moreover, the trans ring isomer turns out to be $24 \mathrm{kcal} / \mathrm{mol}$ more stable than the cis ring isomer. This way, it is clear that there are two possible reaction channels for the 8,12-cyclization in the active site of the enzyme, the cis and the trans channel. The geometric difference between them turns out to be extremely subtle, and 


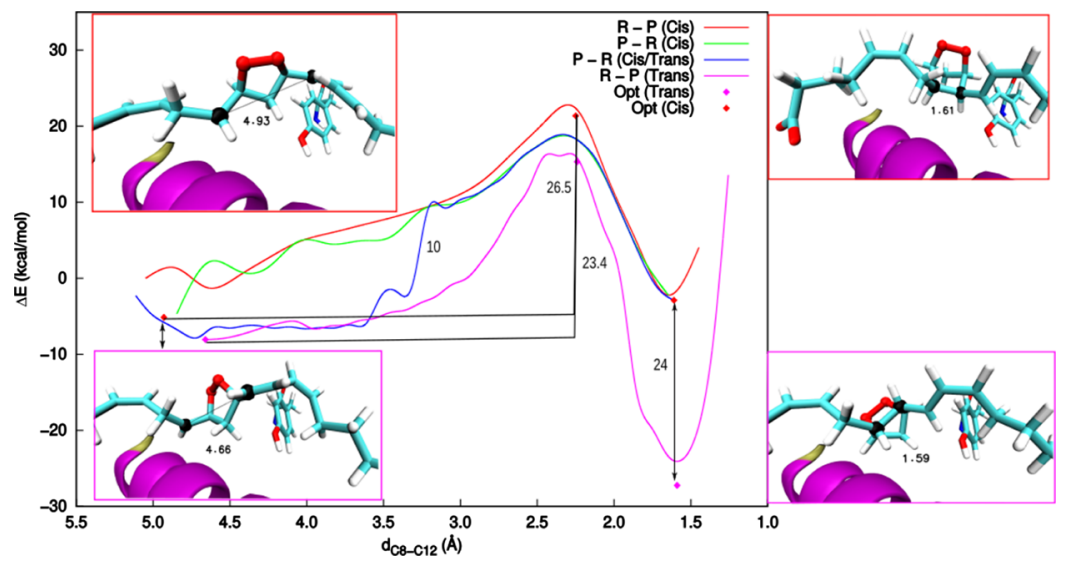

Figure 9. Forward (red line) and backward (green line) potential energy profiles corresponding to the formation of the cis ring isomer of snapshot I. The red diamonds stand for the optimized stationary points of the cis reaction. The upper insets contain pictures of the reactant (left, pre cis) and product (right, cis). The blue line is the backward profile with a shorter optimization step size. The purple line is a forward potential energy profile starting from the new structure of the reactant (pre trans) and leading to the natural trans ring isomer. The purple diamonds stand for the optimized stationary points of the trans reaction. The lower insets contain pictures of the reactant (left, pre trans) and product (right, trans). The distances are given in $\AA$ and the energies in $\mathrm{kcal} / \mathrm{mol}$. Carbon atoms $\mathrm{C}_{8}$ and $\mathrm{C}_{12}$ are depicted in black and oxygen atoms in red.

the system can fall in either of the two channels depending on how the potential energy profile is built. In Figure S5, it is shown how a clockwise or an anticlockwise rotation of the endoperoxide group, which is accompanied by the corresponding motion of the cyclopentane ring, as going along the backward potential energy profile transforms the bicyclo endoperoxide from a pre cis structure to a pre trans one (green line to blue line) or not (the system holds on the green line), respectively, between the values $3.2-3.5 \AA$ of the $\mathrm{C}_{8}-$ $\mathrm{C}_{12}$ reaction coordinate. Thus, COX-2 controls the stereochemistry of the 8,12-cyclization by means of the spatial positions of the side chains of its active site residues, thus producing quite more stable trans ring isomers and with a faster rate than the corresponding cis ring isomers, in such a way that the natural PGG2 generated by COX-2 only contains the trans ring isomer of the bicyclo endoperoxide. Conversely, in solution, when that enzyme environment is absent, it is the cis ring isomer the one that is mostly produced. The same conclusion can be reached analyzing the behavior of snapshot II (Figure S6), where the potential energy barriers for the formation of the trans or cis ring isomer are, respectively, 17.5 or $24.1 \mathrm{kcal} / \mathrm{mol}$, the first one $16.2 \mathrm{kcal} / \mathrm{mol}$ being more stable. Note that our results allow us to override one of the points argued by Dean and Dean ${ }^{10}$ in favor of their carbocation-based mechanism (see above).

The fifth step consists of the addition of $\mathrm{O}_{2}$ to $\mathrm{C}_{15}$. Starting from the optimized $\mathrm{C}_{13}-\mathrm{C}_{15}$ allyl radical trans ring isomers obtained after the fourth step for snapshots I and II we have followed a strategy similar to the one adopted for the $\mathrm{O}_{2}$ addition to $\mathrm{C}_{11}$ in the second step. The potential energy barriers obtained for all the pathways (with the $\mathrm{O}-\mathrm{C}_{15}$ distance taken as the reaction coordinate) that have been able to reach the products (peroxyl radicals at $\mathrm{C}_{15}$ ) for both snapshots are given in Table 4. Both the $15 \mathrm{R}$ and the $15 \mathrm{~S}$ additions are possible for snapshot I, although only the $15 \mathrm{~S}$ stereochemistry is reached in the case of snapshot II. In all cases, the potential energy barriers are relatively small.

The sixth and last step of the all-radical mechanism consists of the back hydrogen transfer from Tyr385 to the peroxyl radicals at $\mathrm{C}_{15}$ formed in the fifth step. We have taken the unbonded oxygen $-\mathrm{H}$ distance to define the reaction
Table 4. Potential Energy Barriers (kcal/mol) Corresponding to the Oxygen Addition to $C_{15}$ for all the Pathways That Have Been Able To Reach the Products for Snapshots I and II

\begin{tabular}{ccccc}
\multicolumn{2}{c}{ snapshot I } & & \multicolumn{2}{c}{ snapshot II } \\
\cline { 1 - 2 } \cline { 5 - 5 }$\Delta E^{\ddagger}$ & stereochemistry $\mathrm{C}_{15}$ & & $\Delta E^{\ddagger}$ & stereochemistry $\mathrm{C}_{15}$ \\
2.6 & $\mathrm{R}$ & & 2.4 & $\mathrm{~S}$ \\
6.8 & $\mathrm{~S}$ & & 2.5 & $\mathrm{~S}$ \\
\hline
\end{tabular}

coordinate. In the case of snapshot I, the peroxyl group has to first rotate the unbonded oxygen in order to become close to the hydrogen atom of Tyr385 that will be abstracted. This rotation involves two small potential energy barriers (see Figure S7) preceding the energy rise corresponding to the hydrogen abstraction itself. We can observe in Table 5 that the

Table 5. Potential Energy Barriers ( $\mathrm{kcal} / \mathrm{mol}$ ) Corresponding to the Back Hydrogen Transfer from Tyr385 to the Peroxyl Radical at $\mathrm{C}_{15}$

\begin{tabular}{ccccc}
\multicolumn{2}{c}{ snapshot I } & & \multicolumn{2}{c}{ snapshot II } \\
\cline { 1 - 2 } 14.9 & stereochemistry $\mathrm{C}_{15}$ & & $\Delta E^{\ddagger}$ & stereochemistry $\mathrm{C}_{15}$ \\
13.2 & $\mathrm{R}$ & & 11.8 & $\mathrm{~S}$ \\
$\mathrm{~S}$ & $\mathrm{~S}$ & & 10.2 & $\mathrm{~S}$
\end{tabular}

formation of the hydroperoxide group with stereochemistry $15 \mathrm{~S}$ is favored versus the $15 \mathrm{R}$ one. The scenario corresponding to the snapshot II is slightly different. In this case, the peroxyl group formed in the fifth step is already well oriented to abstract the hydrogen atom. No previous rotation is needed. As a consequence, the potential energy barriers (see Table 5) for the two pathways we have built (both of them leading to a $15 S$ hydroperoxide) are smaller than in the case of snapshot I. Thus, the results corresponding to the last two steps show that the oxygen molecule can attack $\mathrm{C}_{15}$ forming either a $15 \mathrm{~S}$ or a $15 \mathrm{R}$ hydroxyl radical, but the formation of the final $15 \mathrm{~S}$ hydroperoxide is faster enough than the formation of the final $15 \mathrm{R}$ hydroperoxide to explain why only the $15 \mathrm{~S}$ PGG2 is found experimentally. ${ }^{55}$ Then, we have shown that the allradical mechanism is able to account for the chirality at $\mathrm{C}_{15}$, no 
invocation to the carbocation-based mechanism being necessary.

3.2.2. Carbocation-Based Mechanism. As mentioned in the Introduction, a central point in this mechanism ${ }^{10}$ is the sigmatropic hydrogen transfer from $\mathrm{C}_{10}$ to $\mathrm{C}_{13}$, giving a delocalized $\mathrm{C}_{8}-\mathrm{C}_{12}$ pentadienyl radical. Starting from the optimized products after the $\mathrm{H}_{13 \mathrm{~A}}$ abstraction from AA by the tyrosyl radical (see above), we have chosen the $\mathrm{H}_{10}-\mathrm{C}_{13}$ distance to determine the potential energy profiles for that hydrogen transfer. The potential energy barriers are 34.5 and $40.5 \mathrm{kcal} / \mathrm{mol}$ for the snapshots I and II, respectively. These very high barriers discard the carbocation-based mechanism. This process would transform an AA with a nonplanar $\mathrm{C}_{8}-\mathrm{C}_{12}$ fragment and a planar pentadienyl radical delocalized over $\mathrm{C}_{11}-\mathrm{C}_{15}$ to an $\mathrm{AA}$ with a planar pentadienyl radical delocalized over $\mathrm{C}_{8}-\mathrm{C}_{12}$ and a nonplanar $\mathrm{C}_{11}-\mathrm{C}_{15}$ fragment (the corresponding stationary points for snapshot $\mathrm{I}$ are pictured in Figure 10). This fact involves a considerable rearrangement

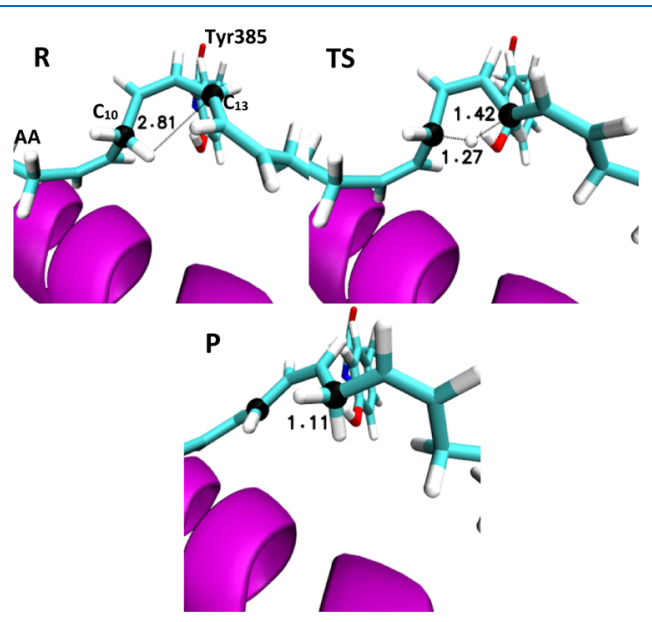

Figure 10. Stationary points corresponding to the sigmatropic hydrogen transfer from $\mathrm{C}_{10}$ to $\mathrm{C}_{13}$ according to the carbocationbased mechanism for snapshot I. R, TS, and P stand for the reactant, transition state structure, and product, respectively. The distances are given in $\AA$. Carbon atoms $\mathrm{C}_{10}$ and $\mathrm{C}_{13}$ are depicted in black.

of AA that inside the active site of COX-2 causes those huge energy barriers. That hydrogen transfer could be feasible in a short hydrocarbon radical in solution, but this is not the case.

Thus, our results confirm the electron paramagnetic resonance experiments which do not detect a pentadienyl radical delocalized over $\mathrm{C}_{8}-\mathrm{C}_{12}$, but over $\mathrm{C}_{11}-\mathrm{C}_{15} .22,56$

On the other hand, the experimental finding ${ }^{21}$ (see the Introduction) that with 10,10-difluoroarachidonic acid as substrate, COX enzymes do not generate any cyclic prostaglandin-like products, but acyclic alcohols such as 10,10-difluoro-11S-hydroxyeicosatetraenoic acid, seems to support the important role of $\mathrm{C}_{10}$ (and, as a consequence, the feasibility of the carbocation based mechanism) for the formation of prostaglandins. Then, we have decided to check what predicts the all-radical mechanism for that substrate. To this aim, we have first substituted the two hydrogen atoms at $\mathrm{C}_{10}$ by two fluorine atoms in the snapshots I and II of the AA radical delocalized over the $\mathrm{C}_{11}-\mathrm{C}_{15}$ planar pentadienyl system generated in the first reaction step (the $\mathrm{H}_{13 \mathrm{~A}}$ abstraction). After optimization, we have followed a procedure similar to the one outlined above to select different possible starting positions of the oxygen molecule and proceed to add the oxygen molecule to $\mathrm{C}_{11}$. For snapshot II, we have found an antarafacial reaction path with a potential energy barrier of $40 \mathrm{kcal} / \mathrm{mol}$ but a suprafacial pathway with a barrier of $13.2 \mathrm{kcal} / \mathrm{mol}$. The corresponding addition products are pictured in Figure 11.

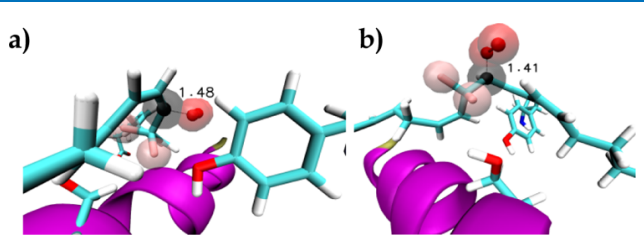

Figure 11. Optimized products of the (a) suprafacial and (b) antarafacial oxygen addition to $\mathrm{C}_{11}$ of the 10,10-difluoroarachidonic acid radical delocalized over the $C_{11}-C_{15}$ planar pentadienyl system for snapshot II. The distances are given in $\AA$. Carbon atom $\mathrm{C}_{11}$ is depicted in black, oxygen atoms in red, and fluorine atoms in pink.

Note that the two fluorine atoms at $\mathrm{C}_{10}$ are antarafacial with respect to the tyrosyl radical. Then, it can be easily understood that they highly prevent the antarafacial molecular oxygen attack, but not the suprafacial one. On the other hand, we have found two suprafacial additions for snapshot I, with barriers of 6.1 and $12.3 \mathrm{kcal} / \mathrm{mol}$. As mentioned above, the suprafacial oxygen attack involves an $11 \mathrm{~S}$ stereochemistry and is not able to produce PGG2. As a consequence, we have demonstrated that the all-radical mechanism does explain why COX-2 converts the substrate 10,10-difluoroarachidonic acid just to the 10,10-difluoro-11S-hydroxyeicosatetraenoic acid, but not to PGG2, no invocation to any special role of $\mathrm{C}_{10}$ (nor to the carbocation based mechanism) being required.

\section{CONCLUSIONS}

COX-2 is one of the two main human enzymes responsible for inflammation and in this sense is an extremely important pharmacologic target of the nonsteroidal anti-inflammatory drugs. COX-2 transforms arachidonic acid, its main substrate, to the lipid pro-inflammatory mediators prostaglandins. In this paper, we have combined molecular dynamics simulations and QM/MM calculations to study the complete reaction mechanism corresponding to the formation of PGG2 in the cyclooxygenase active site of COX-2. We have shown that COX-2 converts AA to PGG2 by means of an all-radical catalytic mechanism ${ }^{16-19}$ that involves six successive reaction steps, including two hydrogen transfers, two $\mathrm{O}_{2}$ additions, and two cyclizations. We have followed the evolution and fate of two pre-catalytic (i.e., ready to react) snapshots taken from the initial molecular dynamics simulation of the enzyme: substrate Michaelis complex. We have found that the main trends of the mechanism are the same for both, although each one retains its own quantitative values. That is, we can infer that, as usual in this kind of enzymatic reactions, there exists a significant dispersion of the initial geometry of the reactants, which produces some dispersion of the quantitative values for each step, but within a common mechanism. Indeed, the quantitative values (for instance, the energy barriers) measured experimentally for the macroscopic reaction come from a probability weighted average over all the possible reactants.

As seen in Figure 12, AA undergoes quite significant distortions in its way to form PGG2. These distortions involve considerable conformational changes (especially from carbon atoms 8 to 15) that are not easy for such a long substrate, that is both flexible (due to its single bonds) and rigid (due to its four $\mathrm{C}=\mathrm{C}$ double bond), and this rigidity increases as the 


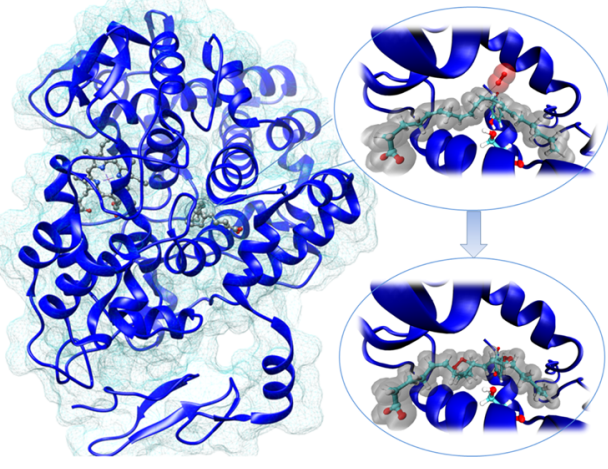

Figure 12. COX-2 showing the two active sites, the peroxidase active site (left) and the cyclooxygenase active site (right). The two elliptic inset corresponds to AA being attacked by an oxygen molecule at the beginning of the second step (up) and to PGG2 formed in the sixth step (down).

successive cyclizations occur. COX-2 uses its relatively narrow channel in the cyclooxygenase active site to restrain the available conformational changes of AA. This is the way how COX-2 manages to catalytically control the exquisite regioselectivity and stereoselectivity of the formation of PGG2, in particular its $11 \mathrm{R}$ and $15 \mathrm{~S}$ final stereochemistry and its trans cyclopentane ring isomer (recall that the allradical mechanism mostly produces the cis cyclopentane ring isomer in solution).

Conversely, the huge potential energy barriers we have found for the postulated hydrogen transfer between carbon atoms 10 and 13 are enough to discard the carbocation based mechanism. ${ }^{10}$ These high barriers are the consequence of the transformation of an AA with a nonplanar $\mathrm{C}_{8}-\mathrm{C}_{12}$ fragment and a planar pentadienyl radical delocalized over $C_{11}-C_{15}$ to an AA with a planar pentadienyl radical delocalized over $\mathrm{C}_{8}-$ $\mathrm{C}_{12}$ and a nonplanar $\mathrm{C}_{11}-\mathrm{C}_{15}$ fragment, a considerable rearrangement of $\mathrm{AA}$ that inside the active site of COX-2 is not feasible. In addition, we have shown that the all-radical mechanism already predicts that COX-2 does not generate PGG2 but just the 10,10-difluoro-11S-hydroxyeicosatetraenoic acid when 10,10-difluoroarachidonic acid is the substrate, this way decaying one of the main arguments in favor of the carbocation based mechanism. ${ }^{10}$

To summarize, we have shown that the formation of PGG2 from AA catalyzed by COX-2 takes place through the allradical catalytic mechanism, and we have explained how this enzyme manages to control the regioselectivity and stereoselectivity of the reaction. We hope that this detailed molecular knowledge can be useful to understand how the nonsteroidal anti-inflammatory drugs act and to design other ones with fewer side effects.

\section{ASSOCIATED CONTENT}

\section{S Supporting Information}

The Supporting Information is available free of charge on the ACS Publications website at DOI: 10.1021/acsomega.8b03575.

QM regions defined for the different steps studied in the all-radical mechanism, evolution of the distances $\mathrm{H}_{13 \mathrm{~A}}-$ OTyr385 and $\mathrm{C}_{13}-\mathrm{OTyr} 385$ along the $150 \mathrm{~ns} \mathrm{MD}$ simulation of AA within the cyclooxygenase active site including Tyr385 of monomer $\mathrm{B}$ of COX-2, evolution of the distances $\mathrm{H}_{13 \mathrm{~A}}-\mathrm{OTyr} 385$ and $\mathrm{C}_{13}-\mathrm{OTyr} 385$ along the $100 \mathrm{~ns} \mathrm{MD}$ simulation of AA within the cyclooxygenase active site including theTyr $385^{\circ}$ radical of monomer B of COX-2, view of the antarafacial/ suprafacial concepts, potential energy profiles corresponding to the formation of the cis ring isomer of snapshot I, potential energy profiles corresponding to the formation of the cis ring isomer of snapshot II, potential energy profiles corresponding to the back hydrogen transfer from Tyr385 to the peroxyl radicals at $\mathrm{C}_{15}$ formed in the fifth step of the all-radical mechanism, and atomic spin density information (PDF)

\section{AUTHOR INFORMATION}

\section{Corresponding Author}

*Email: JoseMaria.Lluch@uab.cat.

ORCID $\odot$

Àngels González-Lafont: 0000-0003-0729-2483

José M. Lluch: 0000-0002-7536-1869

\section{Notes}

The authors declare no competing financial interest.

\section{ACKNOWLEDGMENTS}

We thank the Spanish "Ministerio de Ciencia, Innovación y Universidades” for Grant CTQ2017-83745-P. We acknowledge CSUC for computational facilities. We also thank Pedro Alexandrino Fernandes (Universidade do Porto) for helping us to parameterize the tyrosyl radical.

\section{REFERENCES}

(1) Vecchio, A. J.; Simmons, D. M.; Malkowski, M. G. Structural Basis of Fatty Acid Substrate Binding to Cyclooxygenase-2. J. Biol. Chem. 2010, 285, 22152-22163.

(2) Smith, W. L.; DeWitt, D. L.; Garavito, R. M. Cyclooxygenases: Structural, Cellular, and Molecular Biology. Annu. Rev. Biochem. 2000, 69, 145-182.

(3) Mitchell, J. A.; Akarasereenont, P.; Thiemermann, C.; Flower, R. J.; Vane, J. R. Selectivity of Nonsteroidal Antiinflammatory Drugs as Inhibitors of Constitutive and Inducible Cyclooxygenase. Proc. Natl. Acad. Sci. U.S.A. 1993, 90, 11693-11697.

(4) Tosco, P. A Mechanistic Hypothesis for the Aspirin-Induced Switch in Lipid Mediator Production by Cyclooxygenase-2. J. Am. Chem. Soc. 2013, 135, 10404-10410.

(5) Lei, J.; Zhou, Y.; Xie, D.; Zhang, Y. Mechanistic Insights into a Classic Wonder Drug-Aspirin. J. Am. Chem. Soc. 2014, 137, 70-73.

(6) Orlando, B. J.; Lucido, M. J.; Malkowski, M. G. The Structure of Ibuprofen Bound to Cyclooxygenase-2. J. Struct. Biol. 2015, 189, 6266.

(7) Konkle, M. E.; Blobaum, A. L.; Moth, C. W.; Prusakiewicz, J. J.; Xu, S.; Ghebreselasie, K.; Akingbade, D.; Jacobs, A. T.; Rouzer, C. A.; Lybrand, T. P.; et al. Conservative Secondary Shell Substitution In Cyclooxygenase-2 Reduces Inhibition by Indomethacin Amides and Esters via Altered Enzyme Dynamics. Biochemistry 2015, 55, 348359.

(8) Lucido, M. J.; Orlando, B. J.; Vecchio, A. J.; Malkowski, M. G. Crystal Structure of Aspirin-Acetylated Human Cyclooxygenase-2: Insight into the Formation of Products with Reversed Stereochemistry. Biochemistry 2016, 55, 1226-1238.

(9) Orlando, B. J.; Borbat, P. P.; Georgieva, E. R.; Freed, J. H.; Malkowski, M. G. Pulsed Dipolar Spectroscopy Reveals That Tyrosyl Radicals Are Generated in Both Monomers of the Cyclooxygenase-2 Dimer. Biochemistry 2015, 54, 7309-7312.

(10) Dean, A. M.; Dean, F. M. Carbocations in the Synthesis of Prostaglandins by the Cyclooxygenase of Pgh Synthase? Protein Sci. 1999, 8, 1087-1098. 
(11) Kiefer, J. R.; Pawlitz, J. L.; Moreland, K. T.; Stegeman, R. A.; Hood, W. F.; Gierse, J. K.; Stevens, A. M.; Goodwin, D. C.; Rowlinson, S. W.; Marnett, L. J.; et al. Structural Insights into the Stereochemistry of the Cyclooxygenase Reaction. Nature 2000, 405, 97-101.

(12) Yuan, C.; Rieke, C. J.; Rimon, G.; Wingerd, B. A.; Smith, W. L. Partnering between Monomers of Cyclooxygenase-2 Homodimers. Proc. Natl. Acad. Sci. U.S.A. 2006, 103, 6142-6147.

(13) Silva, P. J.; Fernandes, P. A.; Ramos, M. J. A Theoretical Study of Radical-Only and Combined Radical/Carbocationic Mechanisms of Arachidonic Acid Cyclooxygenation by Prostaglandin H Synthase. Theor. Chem. Acc. 2003, 110, 345-351.

(14) Marnett, L. J. Cyclooxygenase Mechanisms. Curr. Opin. Chem. Biol. 2000, 4, 545-552.

(15) Schneider, C.; Boeglin, W. E.; Lai, S.; Cha, J. K.; Brash, A. R. Synthesis and Applications of Stereospecifically3H-Labeled Arachidonic Acids as Mechanistic Probes for Lipoxygenase and Cyclooxygenase Catalysis. Anal. Biochem. 2000, 284, 125-135.

(16) Hamberg, M.; Samuelsson, B. On the Mechanism of the Biosynthesis of Prostaglandins E-1 and F-1-Alpha. J Biol Chem 1967, 242, 5336-5343.

(17) Marnett, L. J.; Maddipati, K. R. Prostaglandin H Synthase. In Peroxidases in Chemistry and Biology; Everse, J., Everse, K. E., Grisham, M. B., Eds., CRC PRESS, 1991; Vol. 1, pp 293-334.

(18) Smith, W. L.; Marnett, L. J. Prostaglandin Endoperoxide Synthase: Structure and Catalysis. Biochim. Biophys. Acta, Lipids Lipid Metab. 1991, 1083, 1-17.

(19) Schneider, C.; Pratt, D. A.; Porter, N. A.; Brash, A. R. Control of Oxygenation in Lipoxygenase and Cyclooxygenase Catalysis. Chem. Biol. 2007, 14, 473-488.

(20) O'Connor, D. E.; Mihelich, E. D.; Coleman, M. C. Stereochemical Course of the Autoxidative Cyclization of Lipid Hydroperoxides to Prostaglandin-like Bicyclo Endoperoxides. J. Am. Chem. Soc. 1984, 106, 3577-3584.

(21) Kwok, P. Y.; Muellner, F. W.; Fried, J. Enzymatic Conversions of 10,10-Difluoroarachidonic Acid with PGH Synthase and Soybean Lipoxygenase. J. Am. Chem. Soc. 1987, 109, 3692-3698.

(22) Navratil, A. R.; Shchepinov, M. S.; Dennis, E. A. Lipidomics Reveals Dramatic Physiological Kinetic Isotope Effects during the Enzymatic Oxygenation of Polyunsaturated Fatty Acids Ex Vivo. J. Am. Chem. Soc. 2017, 140, 235-243.

(23) Maier, J. A.; Martinez, C.; Kasavajhala, K.; Wickstrom, L.; Hauser, K. E.; Simmerling, C. Ff14SB: Improving the Accuracy of Protein Side Chain and Backbone Parameters from Ff99SB. J. Chem. Theory Comput. 2015, 11, 3696-3713.

(24) Case; Babin, V.; Berryman, J.; Betz, R.; Cai, Q.; Cerutti, D.; Cheatham, T.; Darden, T.; Duke, R.; Gohlke, H.; et al. Amber 14Reference Manual. 2014.

(25) Jorgensen, W. L.; Chandrasekhar, J.; Madura, J. D.; Impey, R. W.; Klein, M. L. Comparison of Simple Potential Functions for Simulating Liquid Water. J. Chem. Phys. 1983, 79, 926-935.

(26) Klein, C. I.; Cieplak, P.; Cornell, W.; Kollman, P. A. A WellBehaved Electrostatic Potential Based Method Using Charge Restraints for Deriving Atomic Charges: The RESP Model. 2002.

(27) Shahrokh, K.; Orendt, A.; Yost, G. S.; Cheatham, T. E. Quantum Mechanically Derived AMBER-Compatible Heme Parameters for Various States of the Cytochrome P450 Catalytic Cycle. J. Comput. Chem. 2011, 33, 119-133.

(28) Wang, J.; Wolf, R. M.; Caldwell, J. W.; Kollman, P. A.; Case, D. A. Development and Testing of a General Amber Force Field. J. Comput. Chem. 2004, 25, 1157-1174.

(29) Lee, C.; Yang, W.; Parr, R. G. Development of the ColleSalvetti Correlation-Energy Formula into a Functional of the Electron Density. Phys. Rev. B 1988, 37 (2), 785-789, DOI: 10.1103/ PhysRevB37.785.

(30) Becke, A. D. Density-Functional Thermochemistry. III. The Role of Exact Exchange. J. Chem. Phys. 1993, 98, 5648-5652.
(31) Hariharan, P. C.; Pople, J. A. The Influence of Polarization Functions on Molecular Orbital Hydrogenation Energies. Theor. Chim. Acta. 1973, 28, 213-222.

(32) Francl, M. M.; Pietro, W. J.; Hehre, W. J.; Binkley, J. S.; Gordon, M. S.; DeFrees, D. J.; Pople, J. A. Self-Consistent Molecular Orbital Methods. XXIII. A Polarization-Type Basis Set for SecondRow Elements. J. Chem. Phys. 1982, 77, 3654-3665.

(33) Frisch; Trucks, G.; Schlegel, H.; Scuseria, G.; Robb, M.; Cheeseman, J.; Scalmani, G.; Barone, V.; Mennucci, B.; Petersson, G.; et al. Gaussian 09; Gaussian, Inc.: Wallingford, CT, 2009.

(34) Lei, H.; Baker, N. A.; Li, X. Data-Driven Parameterization of the Generalized Langevin Equation. Proc. Natl. Acad. Sci. U.S.A. 2016, $113,14183-14188$.

(35) Berendsen, H. J. C.; Postma, J. P. M.; van Gunsteren, W. F.; DiNola, A.; Haak, J. R. Molecular Dynamics with Coupling to an External Bath. J. Chem. Phys. 1984, 81, 3684-3690.

(36) Ryckaert, J.-P.; Ciccotti, G.; Berendsen, H. J. C. Numerical Integration of the Cartesian Equations of Motion of a System with Constraints: Molecular Dynamics of n-Alkanes. J. Comput. Phys. 1977, 23, 327-341.

(37) Deserno, M.; Holm, C. How to Mesh up Ewald Sums. I. a Theoretical and Numerical Comparison of Various Particle Mesh Routines. J. Chem. Phys. 1998, 109, 7678-7693.

(38) Le Grand, S.; Götz, A. W.; Walker, R. C. SPFP: Speed without Compromise-A Mixed Precision Model for GPU Accelerated Molecular Dynamics Simulations. Comput. Phys. Commun. 2013, 184, 374-380.

(39) Salomon-Ferrer, R.; Götz, A. W.; Poole, D.; Le Grand, S.; Walker, R. C. Routine Microsecond Molecular Dynamics Simulations with AMBER on GPUs. 2. Explicit Solvent Particle Mesh Ewald. J. Chem. Theory Comput. 2013, 9, 3878-3888.

(40) Sherwood, P.; de Vries, A. H.; Guest, M. F.; Schreckenbach, G.; Catlow, C. R. A.; French, S. A.; Sokol, A. A.; Bromley, S. T.; Thiel, W.; Turner, A. J.; et al. QUASI: A General Purpose Implementation of the QM/MM Approach and Its Application to Problems in Catalysis. J. Mol. Struct.: THEOCHEM 2003, 632, 1-28.

(41) Metz, S.; Kästner, J.; Sokol, A. A.; Keal, T. W.; Sherwood, P. ChemShell-a Modular Software Package for QM/MM Simulations. Wiley Interdiscip. Rev.: Comput. Mol. Sci. 2013, 4, 101-110.

(42) Smith, W.; Forester, T. R. DL_POLY_2.0: A general-purpose parallel molecular dynamics simulation package. J. Mol. Graphics 1996, 14, 136-141.

(43) Bakowies, D.; Thiel, W. Hybrid Models for Combined Quantum Mechanical and Molecular Mechanical Approaches. J. Phys. Chem. 1996, 100, 10580-10594.

(44) Senn, H. M.; Thiel, W. QM/MM Methods for Biomolecular Systems. Angew. Chem., Int. Ed. 2009, 48, 1198-1229.

(45) Liu, D. C.; Nocedal, J. On the Limited Memory BFGS Method for Large Scale Optimization. Math. Program. 1989, 45, 503-528.

(46) Humphrey, W.; Dalke, A.; Schulten, K. VMD: Visual Molecular Dynamics. J. Mol. Graphics 1996, 14, 33-38.

(47) Furse, K. E.; Pratt, D. A.; Schneider, C.; Brash, A. R.; Porter, N. A.; Lybrand, T. P. Molecular Dynamics Simulations of Arachidonic Acid-Derived Pentadienyl Radical Intermediate Complexes with COX-1 and COX-2: Insights into Oxygenation Regio- and Stereoselectivity. Biochemistry 2006, 45, 3206-3218.

(48) Furse, K. E.; Pratt, D. A.; Porter, N. A.; Lybrand, T. P. Molecular Dynamics Simulations of Arachidonic Acid Complexes with COX-1 and COX-2: Insights into. Biochemistry 2006, 45, 31893205.

(49) Saura, P.; Suardíaz, R.; Masgrau, L.; Lluch, J. M.; GonzálezLafont, À. Unraveling How Enzymes Can Use Bulky Residues to Drive Site-Selective c-h Activation: The Case of Mammalian Lipoxygenases Catalyzing Arachidonic Acid Oxidation. ACS Catal. 2014, 4, 4351-4363.

(50) Adel, S.; Karst, F.; González-Lafont, À.; Pekárová, M.; Saura, P.; Masgrau, L.; Lluch, J. M.; Stehling, S.; Horn, T.; Kuhn, H.; et al. Evolutionary Alteration of ALOX15 Specificity Optimizes the 
Biosynthesis of Antiinflammatory and Proresolving Lipoxins. Proc. Natl. Acad. Sci. U.S.A. 2016, 113, E4266-E4275.

(51) Saura, P.; Kaganer, I.; Heydeck, D.; Lluch, J. M.; Kühn, H.; González-Lafont, À. Mutagenesis of Sequence Determinants of Truncated Porcine ALOX15 Induces Changes in the Reaction Specificity by Altering the Catalytic Mechanism of Initial Hydrogen Abstraction. Chem.-Eur. J. 2017, 24, 962-973.

(52) Ribeiro, A. J. M.; Santos-Martins, D.; Russo, N.; Ramos, M. J.; Fernandes, P. A. Enzymatic Flexibility and Reaction Rate: A QM/ MM Study of HIV-1 Protease. ACS Catal. 2015, 5, 5617-5626.

(53) Liu, Y.; Roth, J. P. A Revised Mechanism for Human Cyclooxygenase-2. J. Biol. Chem. 2015, 291, 948-958.

(54) Saura, P.; Suardíaz, R.; Masgrau, L.; González-Lafont, À.; Rosta, E.; Lluch, J. M. Understanding the Molecular Mechanism of the Alaversus-Gly Concept Controlling the Product Specificity in Reactions Catalyzed by Lipoxygenases: A Combined Molecular Dynamics and QM/MM Study of Coral 8R-Lipoxygenase. ACS Catal. 2017, 7, 4854-4866.

(55) Schneider, C.; Boeglin, W. E.; Prusakiewicz, J. J.; Rowlinson, S. W.; Marnett, L. J.; Samel, N.; Brash, A. R. Control of Prostaglandin Stereochemistry at the 15-Carbon by Cyclooxygenases-1 and -2. J. Biol. Chem. 2001, 277, 478-485.

(56) Peng, S.; Okeley, N. M.; Tsai, A.-L.; Wu, G.; Kulmacz, R. J.; van der Donk, W. A. Synthesis of Isotopically Labeled Arachidonic Acids To Probe the Reaction Mechanism of Prostaglandin H Synthase. J. Am. Chem. Soc. 2002, 124, 10785-10796. 